\title{
Risk Factors for Medical and Surgical Complications After Single-Level Minimally Invasive Transforaminal Lumbar Interbody Fusion
}

\author{
ANKUR S. NARAIN, BA, JAMES M. PARRISH, MPH, NATHANIEL W. JENKINS, MS, BRITTANY E.
} HAWS, BS, BENJAMIN KHECHEN, BA, KELLY H. YOM, BA, KRISHNA T. KUDARAVALLI, BS, JORDAN A. GUNTIN, BS, KERN SINGH, MD

Department of Orthopaedic Surgery, Rush University Medical Center, Chicago, Illinois

\begin{abstract}
Background: The prevention of perioperative and postoperative complications is necessary to avoid poor postoperative outcomes and increased costs. Previous investigations have identified risk factors for complications after various spine procedures, but no such study exists in a population solely undergoing minimally invasive transforaminal lumbar interbody fusion (MIS TLIF). The purpose of this study is to determine risk factors for the development of complications up to 2 years after MIS TLIF procedures.

Methods: Patients who underwent primary, single-level MIS TLIF from 2007 to 2016 were retrospectively reviewed. The incidence of medical and surgical complications up to 2 years postoperatively was determined. Patients were categorized according to demographic, comorbidity, and procedural characteristics. Bivariate Poisson regression with robust error variance was used to determine if an association existed between patient characteristics and complication incidence. A final multivariate model including all patient characteristics as controls was created using backwards, stepwise regression until only those variables with $P<.05$ remained.

Results: 390 patients were analyzed. Upon bivariate analysis, age $>50$ years $(P=.025)$, diabetes mellitus $(P=$ $.001)$, and operative duration $>105$ minutes $(P=.016)$ were associated with increased medical complication rates. Regarding surgical complications, age $\leq 50$ years $(P<.001)$, obesity $(P=.012)$, and diabetes mellitus $(P=.042)$ were identified as risk factors on bivariate analysis. Upon final multivariate analysis, operative time $>105$ minutes $(P=.009)$ and diabetes mellitus $(P=.001)$ were independent risk factors for medical complications. Independent risk factors for surgical complications on multivariate analysis included age $\leq 50$ years $(P<.001)$, diabetes mellitus $(P=.002)$, and obesity $(P=.030)$.

Conclusions: Diabetic patients and those who underwent longer operations were at increased risk of medical complications, while younger patients, obese patients and those also with diabetes mellitus were at increased risk of surgical complications up to 2 years after MIS TLIF. Practitioners can use this information to identify patients who require preventative care before their procedure or increased postoperative vigilance and monitoring after single-level MIS TLIF.
\end{abstract}

Level of Evidence: 3.

Minimally Invasive Surgery

Keywords: minimally invasive, TLIF, complications, medical, surgical, diabetes, obesity, age

\section{INTRODUCTION}

Transforaminal lumbar interbody fusion (TLIF) is an effective treatment option for degenerative lumbar spine disease. Minimally invasive techniques (MIS) have been adapted to TLIF in an effort to provide an alternative to traditional open approaches. Compared to its open counterpart, MIS TLIF has been associated with significant procedural advantages in the perioperative period. Such advantages include relative reductions in intraopera- tive blood loss, duration of inpatient hospital stay, and postoperative narcotics utilization. ${ }^{1-5}$ Furthermore, MIS TLIF has been demonstrated to be superior to open TLIF in regards to long-term cost effectiveness. ${ }^{1,6,7}$ The perioperative and cost advantages of MIS TLIF have made this procedure an attractive option for spine surgeons in the current healthcare climate.

A primary concern regarding MIS TLIF procedures is the occurrence of perioperative and postoperative complications. Multiple investiga- 
tions have analyzed the rate of complications after MIS TLIF, with reported incidences ranging from $11.0 \%$ to $31.37 \%$ of patients. ${ }^{8-11}$ The observed variability in reported complication rate may be associated with differing complication definitions between studies. Nonetheless, complication avoidance is a paramount concern both for surgeons and hospital administrators aiming to improve patient outcomes and reduce healthcare resource utilization.

To our knowledge, no previous investigation has comprehensively evaluated risk factors for complications in a population consisting only of patients undergoing MIS TLIF procedures. As such, the purpose of this study is to determine risk factors for medical and surgical complications up to 2 years postoperatively in a patient population undergoing primary, single-level MIS TLIF.

\section{MATERIALS AND METHODS}

\section{Patient Population}

Institutional review board approval was obtained for this study (ORA 14051301). A prospectively maintained surgical registry of patients was retrospectively reviewed. Patients were included in this analysis if they had undergone primary, single-level MIS TLIF for degenerative lumbar spine pathology between 2008 and 2015. All procedures were performed by the senior author (K.S.) at a single academic institution. Patients were excluded if 2 years had not elapsed since their procedure, or if they underwent operative therapy for nondegenerative pathology.

\section{Surgical Technique}

All patients underwent a single-level MIS TLIF using a similar technique. The laminectomy, bilateral facetectomy, and TLIF were performed through a unilateral exposure using a 21-mm nonexpendable tube. After subtotal discectomy, interbody cage instrumentation was packed with local bone graft and an extra-small kit of bone morphogenic protein (BMP-2, Medtronic, Memphis, Tennessee). The cage was then appropriately placed within the intervertebral space. Between 2008 and 2012, nonexpandable poly-ether-etherketone (PEEK) and titanium alloy were both utilized; from 2012 to 2015, nonexpandable PEEK cages were used exclusively. Bilateral or unilateral pedicle screws were percutaneously placed over a guide wire, with the majority of patients $(58 \%)$ undergoing bilateral pedicle screw placement.

\section{Data Collection}

All data were obtained from the aforementioned surgical registry. Patients were classified according to demographic, comorbidity, and operative factors. Demographic factors included age $(\leq 50$ years, $>50$ years), sex, body mass index $\left(<30 \mathrm{~kg} / \mathrm{m}^{2}, \geq 30 \mathrm{~kg} /\right.$ $\mathrm{m}^{2}$ ), and smoking status. Analyzed comorbidity factors included American Society of Anesthesiologists classification $(\leq 2,>2)$, modified Charlson Comorbidity Index $(<1, \geq 1)$, hypertension, and diabetes mellitus. The Charlson Comorbidity Index was modified with the age component removed to allow for the use of both modified Charlson Comorbidity Index and age as individual predictors within subsequent statistical analyses. Operative factors included preoperative Visual Analogue Scale pain score $(<7, \geq 7)$, operative time $(\leq 105$ minutes, $>105$ minutes), and estimated intraoperative blood loss $(\leq 50 \mathrm{~mL},>50 \mathrm{~mL})$.

Complications were identified up to 2 years postoperatively after MIS TLIF. Medical complications measured included urinary retention, altered mental status, ileus, postoperative transfusion requirement, cardiac arrhythmia, acute renal failure, urinary tract infection, aspiration or reintubation, deep venous thrombosis, pulmonary embolism, pneumothorax, and pneumonia. Urinary retention was classified as a complication if postoperative recatheterization was required. Surgical complications measured included pseudarthrosis, instrumentation failure, epidural hematoma, durotomy, surgical site infection, musculoskeletal or bone pathologies, and neurologic dysfunction. Pseudarthrosis was identified via computed tomography scan at 6 months or 1 year postoperatively, and was classified as a complication if the patient had recurrent symptomatology requiring an index-level reoperation. Instrumentation failure was classified as a complication if index-level reoperation was required secondary to the development of new or recurrent clinical symptomatology. Surgical site infection was classified as a complication if an incision and drainage procedure was required postoperatively.

\section{Statistical Analysis}

Statistical analysis was performed using Stata/ MP 13.1 for Mac (StataCorp LP, College Station, 
Table 1. Patient population characteristics.

\begin{tabular}{|c|c|}
\hline Parameter & No. $(\%)$ \\
\hline Total & 390 \\
\hline \multicolumn{2}{|l|}{ Age, y } \\
\hline$\leq 50$ & $172(44.1)$ \\
\hline$>50$ & $218(55.9)$ \\
\hline \multicolumn{2}{|l|}{ Sex } \\
\hline Male & $161(41.3)$ \\
\hline Female & $229(58.7)$ \\
\hline \multicolumn{2}{|l|}{ Body mass index, $\mathrm{kg} / \mathrm{m}^{2}$} \\
\hline$<30$ & $209(53.7)$ \\
\hline$\geq 30$ & $180(46.3)$ \\
\hline \multicolumn{2}{|l|}{ Current smoker } \\
\hline No & $299(76.9)$ \\
\hline Yes & $90(23.1)$ \\
\hline \multicolumn{2}{|l|}{ ASA score } \\
\hline$\leq 2$ & $322(82.6)$ \\
\hline$>2$ & $68(17.4)$ \\
\hline \multicolumn{2}{|c|}{ Ageless Charlson Comorbidity Index } \\
\hline$<1$ & $133(34.1)$ \\
\hline$\geq 1$ & $257(65.9)$ \\
\hline \multicolumn{2}{|l|}{ Hypertension } \\
\hline No & $230(59.1)$ \\
\hline Yes & $159(40.9)$ \\
\hline \multicolumn{2}{|l|}{ Diabetic status } \\
\hline No diabetes mellitus & $342(87.7)$ \\
\hline Diabetes mellitus & $48(12.3)$ \\
\hline \multicolumn{2}{|c|}{ Preoperative VAS pain score } \\
\hline$<7$ & $148(41.0)$ \\
\hline$\geq 7$ & $213(59.0)$ \\
\hline \multicolumn{2}{|l|}{ Operative duration, $\min$} \\
\hline$\leq 105$ & $191(49.0)$ \\
\hline$>105$ & $199(51.0)$ \\
\hline \multicolumn{2}{|l|}{ Estimated blood loss, $\mathrm{mL}$} \\
\hline$\leq 50$ & $272(69.7)$ \\
\hline$>50$ & $118(30.3)$ \\
\hline
\end{tabular}

Abbreviations: ASA, American Society of Anesthesiologists; VAS, Visual Analog Scale.

Texas). Bivariate Poisson regression with robust error variance was utilized to determine if an association existed between each patient characteristic and the incidence of medical or surgical complications. Multivariate Poisson regression was utilized to create a backwards, stepwise model to identify independent predictors of medical or surgical complications. Each patient characteristic was used as a predictor, and predictors were sequentially excluded until only those with significant $P$ values remained. Statistical significance was set at $P<.05$.

\section{RESULTS}

Three hundred ninety patients underwent primary, single-level MIS TLIF and were included in this analysis. Approximately $95 \%$ of patients MIS TLIF at either the L4-L5 $(\mathrm{n}=194)$ and L5-S1 $(\mathrm{n}=178)$ surgical level; a small minority of procedures involved the L3-L4 $(n=16)$ or L2-L3 $(n=2)$ segments. Patient characteristics are presented in Table 1.
Table 2. Incidence of medical and surgical complications.

\begin{tabular}{lc}
\hline Complication & No. $(\mathbf{\%})^{\mathrm{a}}$ \\
\hline Medical & $61(15.6)$ \\
Urinary retention $^{\mathrm{b}}$ & $40(10.3)$ \\
Altered mental status & $6(1.5)$ \\
Ileus & $4(1.0)$ \\
Postoperative transfusion & $4(1.0)$ \\
Arrhythmia & $2(0.5)$ \\
Acute renal failure & $2(0.5)$ \\
UTI & $2(0.5)$ \\
Aspiration/reintubation & $1(0.3)$ \\
DVT & $0(0.0)$ \\
PE & $0(0.0)$ \\
Pneumothorax & $0(0.0)$ \\
Pneumonia & $0(0.0)$ \\
Surgical & $53(13.6)$ \\
Pseudarthrosis & $34(8.7)$ \\
Instrumentation failure & $\mathrm{d}$ \\
Epidural hematoma & $3(0.8)$ \\
Durotomy & $2(0.5)$ \\
Surgical site infection & \\
MSK/bone & $2(0.5)$ \\
Neurologic dysfunction & $2(0.5)$ \\
\hline
\end{tabular}

Abbreviations: DVT = deep venous thrombosis; $\mathrm{MSK}=$ musculoskeletal; $\mathrm{PE}=$ pulmonary embolism; UTI, urinary tract infection.

${ }^{\mathrm{a}} \mathrm{N}=390$.

${ }^{\mathrm{b}}$ Urinary retention requiring recatheterization.

${ }^{\mathrm{c}}$ Pseudarthrosis identified via computed tomography scan with accompanying symptomatology requiring index-level reoperation.

${ }^{\mathrm{d}}$ Cage subsidence $(\mathrm{n}=2)$ and cage migration $(\mathrm{n}=1)$ requiring reoperation.

${ }^{\text {e}}$ Surgical site infection requiring incision and drainage.

The rate of medical complications within this population was $15.6 \%$, with the most prominent complication being postoperative urinary retention $(\mathrm{n}=40,10.3 \%)$. The rate of surgical complications was $11.3 \%$, with the most prominent complication being pseudarthrosis requiring index-level reoperation $(\mathrm{n}=34,8.7 \%)$. The incidence of all measured medical and surgical complications is presented in Table 2.

Upon bivariate analysis, predictors of medical complications included: age $>50$ years (relative risk $[\mathrm{RR}]=1.9,95 \%$ confidence interval $[95 \% \mathrm{CI}]=$ 1.08-3.25, $P=.025)$, diabetes mellitus $(\mathrm{RR}=2.5$, $95 \% \mathrm{CI}=1.47-4.23, \quad P=.001)$, and operative duration $>105$ minutes $(\mathrm{RR}=1.9,95 \% \mathrm{CI}=1.13$ 3.26, $P=.016$, Table 3). Upon bivariate analysis, predictors of surgical complications included: age $\leq 50$ years $(\mathrm{RR}=4.1,95 \% \mathrm{CI}=2.17-7.91, P<$ $.001)$, body mass index $\geq 30 \mathrm{~kg} / \mathrm{m}^{2}(\mathrm{RR}=2.0,95 \%$ $\mathrm{CI}=1.17-3.59, P=.012)$, and diabetes mellitus (RR $=1.9,95 \% \mathrm{CI}=1.02-3.62, P=.0242$, Table 4$)$.

Upon multivariate analysis, the following were identified as independent predictors of medical complications: operative time $>105$ minutes $(\mathrm{RR}=$ $2.2,95 \% \mathrm{CI}=1.22-4.14, P=.009)$ and diabetes mellitus $(\mathrm{RR}=2.7,95 \% \mathrm{CI}=1.52-4.64, P=.001$, Table 5). Multivariate analysis identified the following as independent predictors of surgical com- 
Table 3. Bivariate analysis for medical complications. ${ }^{a}$

\begin{tabular}{|c|c|c|c|c|}
\hline & $\begin{array}{c}\text { Complication } \\
\text { Rate, \% }\end{array}$ & $\mathbf{R R}$ & $95 \% \mathrm{CI}$ & $P$ Value $^{\mathrm{b}}$ \\
\hline \multicolumn{5}{|l|}{ Age, $y$} \\
\hline$\leq \mathbf{5 0}$ & 9.3 & Ref. & & \\
\hline$>\mathbf{5 0}$ & 17.3 & 1.9 & $1.08-3.25$ & .025 \\
\hline \multicolumn{5}{|l|}{ Sex } \\
\hline Male & 14.0 & 1.0 & $0.62-1.69$ & .931 \\
\hline Female & 13.7 & Ref. & & \\
\hline \multicolumn{5}{|l|}{ Body mass index, $\mathrm{kg} / \mathrm{m}^{2}$} \\
\hline$<30$ & 14.8 & Ref. & & \\
\hline$\geq 30$ & 12.2 & 0.8 & $0.50-1.37$ & .456 \\
\hline \multicolumn{5}{|l|}{ Cürent smoker } \\
\hline No & 14.7 & Ref. & & \\
\hline Yes & 11.1 & 0.8 & $0.40-1.44$ & .394 \\
\hline \multicolumn{5}{|l|}{ ASA score } \\
\hline$\leq 2$ & 12.7 & Ref. & & \\
\hline$>2$ & 19.1 & 1.5 & $0.85-2.65$ & .160 \\
\hline \multicolumn{5}{|c|}{ Ageless Charlson Comorbidity Index } \\
\hline$<1$ & 12.8 & Ref. & & \\
\hline$\geq 1$ & 14.4 & 1.1 & $0.66-1.92$ & .663 \\
\hline \multicolumn{5}{|l|}{ Hypertension } \\
\hline No & 11.3 & Ref. & & \\
\hline Yes & 17.6 & 1.6 & $0.95-2.55$ & .079 \\
\hline \multicolumn{5}{|l|}{ Diabetic status } \\
\hline No diabetes mellitus & 11.7 & Ref. & & \\
\hline Diabetes mellitus & 29.2 & 2.5 & $1.47-4.23$ & .001 \\
\hline \multicolumn{5}{|c|}{ Preoperative VAS pain score } \\
\hline$<7$ & 9.5 & Ref. & & \\
\hline$\geq 7$ & 15.0 & 1.6 & $0.88-2.87$ & .126 \\
\hline \multicolumn{5}{|l|}{ Operative duration, min } \\
\hline$\leq \mathbf{1 0 5}$ & 9.4 & Ref. & & \\
\hline$>105$ & 18.1 & 1.9 & $1.13-3.26$ & .016 \\
\hline \multicolumn{5}{|c|}{ Estimated blood loss, $\mathrm{mL}$} \\
\hline$\leq 50$ & 12.5 & Ref. & & \\
\hline$>50$ & 17.0 & 1.4 & $0.82-2.26$ & .241 \\
\hline
\end{tabular}

Abbreviations: 95\% CI, 95\% confidence interval; ASA, American Society of Anesthesiologists; VAS, Visual Analog Scale; Ref., reference; RR, relative risk.

${ }^{\mathrm{a} B}$ Boldface indicates statistical significance.

${ }^{\mathrm{b}} P$ value calculated using Poisson regression with robust error variance.

plications: age $\leq 50$ years $(\mathrm{RR}=4.2,95 \% \mathrm{CI}=2.22$ $8.12, P<.001)$, diabetes mellitus $(\mathrm{RR}=2.7,95 \% \mathrm{CI}$ $=1.25-4.15, P=.002)$, and obesity $(\mathrm{RR}=1.8,95 \%$ $\mathrm{CI}=1.06-3.17, P=.30)$.

\section{DISCUSSION}

MIS TLIF is an increasingly utilized surgical therapy for degenerative lumbar disease. Compared to open TLIF, MIS TLIF has demonstrated significant advantages in the perioperative period pertaining to operative blood loss, length of stay, and postoperative pain. ${ }^{1-5}$ However, concerns regarding the incidence of complications remain paramount for spine practitioners. As such, the purpose of this study was to determine independent risk factors for the incidence of medical or surgical complications up to 2 years postoperatively after MIS TLIF.

The medical complication rate in this study was $15.6 \%$, with the most prominent complication being postoperative urinary retention. The surgical com-
Table 4. Bivariate analysis for surgical complications. ${ }^{\text {a }}$

\begin{tabular}{|c|c|c|c|c|}
\hline & $\begin{array}{c}\text { Complication } \\
\text { Rate, \% }\end{array}$ & $\mathbf{R R}$ & $95 \%$ CI & $P$ Value $^{\mathrm{b}}$ \\
\hline \multicolumn{5}{|l|}{ Age, $y$} \\
\hline$\leq \mathbf{5 0}$ & 20.9 & 4.1 & 2.17-7.91 & $<.001$ \\
\hline$>\mathbf{5 0}$ & 5.1 & Ref. & & \\
\hline \multicolumn{5}{|l|}{ Sex } \\
\hline Male & 13.1 & 1.2 & $0.71-2.17$ & .451 \\
\hline Female & 10.6 & Ref. & & \\
\hline \multicolumn{5}{|l|}{ Body mass index, $\mathrm{kg} / \mathrm{m}^{2}$} \\
\hline$<\mathbf{3 0}$ & 8.1 & Ref. & & \\
\hline$\geq \mathbf{3 0}$ & 16.7 & 2.0 & $1.17-3.59$ & .012 \\
\hline \multicolumn{5}{|l|}{ Current smoker } \\
\hline No & 10.4 & Ref. & & \\
\hline Yes & 17.8 & 1.7 & $0.98-2.99$ & .057 \\
\hline \multicolumn{5}{|l|}{ ASA score } \\
\hline$\leq 2$ & 12.4 & Ref. & & \\
\hline$>2$ & 10.3 & 0.8 & $0.39-1.78$ & .628 \\
\hline \multicolumn{5}{|c|}{ Ageless Charlson Comorbidity Index } \\
\hline$<1$ & 11.3 & Ref. & & \\
\hline$\geq 1$ & 12.5 & 1.1 & $0.62-1.97$ & .737 \\
\hline \multicolumn{5}{|l|}{ Hypertension } \\
\hline No & 10.0 & Ref. & & \\
\hline Yes & 13.8 & 1.3 & $0.74-2.18$ & .378 \\
\hline \multicolumn{5}{|l|}{ Diabetic status } \\
\hline No diabetes mellitus & 10.8 & Ref. & & \\
\hline Diabetes mellitus & 20.8 & 1.9 & $1.02-3.62$ & .042 \\
\hline \multicolumn{5}{|c|}{ Preoperative VAS pain score } \\
\hline$<7$ & 9.5 & Ref. & & \\
\hline$\geq 7$ & 14.1 & 1.5 & $0.82-2.71$ & .193 \\
\hline \multicolumn{5}{|l|}{ Operative duration, $\min$} \\
\hline$\leq 105$ & 14.7 & Ref. & & \\
\hline$>105$ & 9.6 & 0.7 & $0.38-1.13$ & .125 \\
\hline \multicolumn{5}{|c|}{ Estimated blood loss, $\mathrm{mL}$} \\
\hline$\leq 50$ & 12.5 & Ref. & & \\
\hline$>50$ & 11.0 & 0.9 & $0.48-1.61$ & .681 \\
\hline
\end{tabular}

Abbreviations: 95\% CI, 95\% confidence interval; ASA, American Society of Anesthesiologists; Ref., reference; RR, relative risk; VAS, Visual Analog Scale.

${ }^{\text {a } B o l d f a c e ~ i n d i c a t e s ~ s t a t i s t i c a l ~ s i g n i f i c a n c e ~}$

${ }^{\mathrm{b}} P$ value calculated using Poisson regression with robust error variance.

plication rate was $13.6 \%$, with the most frequent complication being pseudarthrosis. Independent risk factors for medical complications included operative time $>105$ minutes and diabetic status. Independent risk factors for surgical complications included age $\leq 50$ years, diabetic status, and obesity.

The results of this study indicate that longer operative times were associated with increased rates of medical complications after MIS TLIF. This result is corroborated within the spine literature, with the most comprehensive analysis of operative time provided by Kim et al. ${ }^{12,13}$ In a study of 4588 patients from the National Surgical Quality Improvement Program database, the authors demonstrated a marginal increase in 30-day medical complication rate with increasing operative time. ${ }^{13}$ Additionally, operative times greater than 2 hours were associated with a 2-fold increased incidence of medical complications. The observed association between medical complications and longer operative times has multiple potential etiologies, such as 
Table 5. Independent risk factors for complications.

\begin{tabular}{lccr}
\hline Complication & RR & 95\% CI & P Value $^{\text {a }}$ \\
\hline Medical & & & \\
$\quad$ Operative time $>105$ mins & 2.2 & $1.22-4.14$ & .009 \\
$\quad$ Diabetes mellitus & 2.7 & $1.52-4.64$ & .001 \\
Surgical & & & \\
$\quad$ Age $\leq 50$ years & 4.2 & $2.22-8.12$ & $<.001$ \\
$\quad$ Diabetes mellitus & 2.7 & $1.25-4.15$ & .002 \\
$\quad$ Body mass index & 1.8 & $1.06-3.17$ & .030 \\
\hline
\end{tabular}

Abbreviations: 95\% CI, 95\% confidence interval; RR, relative risk.

${ }^{a} P$ value calculated using stepwise Poisson regression with robust error variance controlling for age, gender, smoking status, diabetes mellitus, hypertension,

obesity, American Society of Anesthesiologists score, comorbidity burden,

average preoperative pain scores, operative time, and estimated blood loss.

increased surgical complexity and anesthesia times. ${ }^{14-16}$ Longer anesthesia time, specifically, has been associated with increased rates of postoperative urinary retention after spine and other surgical procedures. ${ }^{15,16}$ In relation to postoperative care, patients undergoing prolonged procedures should be more carefully monitored for medical complications. Furthermore, additional investigation analyzing predictive factors for prolonged operative times may aid surgeons in actively attempting to reduce operative times in at-risk patients.

Diabetes mellitus was identified as a predictive factor for both medical and surgical complications after MIS TLIF. Our result is in agreement with much of the spine literature, which has analyzed populations primarily consisting of mixed surgical cohorts. ${ }^{17-23}$ Cook et al, ${ }^{22}$ in a study of 37322 patients undergoing cervical fusion from the Nationwide Inpatient Sample database, determined that the presence of diabetes was associated with increased complication incidence. Specifically, diabetic patients had a greater incidence of cardiac complications and non-home discharge. Guzman et $\mathrm{al}^{20}$ also utilized the Nationwide Inpatient Sample database to perform a similar study of 403629 patients undergoing lumbar surgery for degenerative pathology. In that investigation, diabetic patients were found to be more likely to experience medical complications involving the cerebrovascular, respiratory, cardiac, and genitourinary systems. The etiology of increased medical complications in diabetic patients has been theorized to result from diabetes-related impairments to the systemic inflammatory response. ${ }^{18,23}$ Diabetic status has also been associated with longer lengths of inpatient stay, yielding an increase in risk for complications associated with exposure to nosocomial settings. ${ }^{18-20,22,23}$ Recent literature has also suggested that uncontrolled diabetes may further increase the rate of complications compared to controlled diabetes, indicating a potential role for improved preoperative glycemic control measures in diabetic patients undergoing spinal surgery. ${ }^{20}$

Regarding surgical complications, age $\leq 50$ years was associated with greater complication rate after MIS TLIF. The literature regarding patient age and complications after spinal surgery is variable, with a subset of investigations reporting contradictory findings that older age is associated with increased complication incidence. $^{24-27}$ In a study of 6253 anterior cervical discectomy and fusion patients from the National Surgical Quality Improvement Program database, Buerba et $\mathrm{al}^{27}$ demonstrated that age $\geq 65$ years was associated with a higher incidence of one or more complication up to 30 days postoperatively. Other studies, however, have determined that age is not a risk factor for surgical complications after spinal procedures. ${ }^{28,29}$ Kilincer et $\mathrm{al}^{29}$ performed a study of 129 patients undergoing lumbar decompression and fusion. In that investigation, a matched cohort subanalysis of 80 patients demonstrated that patients older than 65 years of age did not have increased surgical complication rate compared to those younger than 65 years of age. To our knowledge, the current study is the first to demonstrate increased surgical complication rates in younger patients.

The etiology of this finding is unknown, though it may be multifactorial. Part of this finding could be related to this study's age cutoffs or the overall distribution of age within our study population. Furthermore, while the findings of other studies vary, ${ }^{30}$ characteristics such as smoking, steroid use, and posterior approaches have all been found to potentially contribute to pseudarthrosis. ${ }^{31}$ Younger patients may have increased postoperative activity levels. Although moderate physical activity is typically thought to be beneficial after a lumbar fusion procedure, ${ }^{32,33}$ it may produce additional mechanical stress on the fusion construct. Further research is required to fully elucidate the association between age and surgical complication incidence after MIS TLIF.

This study also determined that obesity was associated with increased surgical complication rates. Within the general spine literature, obesity has been widely associated with increased complication incidence. ${ }^{34-40}$ Regarding surgical complications specifically, multiple studies have demonstrated an association between obesity and 
the incidence of surgical site infections..$^{35,38,39,41,42}$ The increased risk for surgical site infections in obese patients has been attributed to the increased risk of fat necrosis in this population, serving as a nidus for infection. Additionally, when utilizing a posterior approach, obese patients can create a more technically demanding procedure due to limited patient mobility and increased difficulty during surgical exposure. ${ }^{43}$ Nonetheless, further work is still necessary to fully describe the association between obesity and the spectrum of individual surgical complications after MIS TLIF.

This study is not without limitations. First, the retrospective nature of this study may introduce selection bias and prevent controlling for unknown confounders. Second, this study was based off of a population treated by 1 surgeon at a single academic site. Thus, generalizability of the study results may be limited. Third, the sample size was relatively small at 390 patients, resulting in low overall incidences of some complications. As such, it was not possible to statistically compare the rate of individual complications, and they were instead aggregated as either medical or surgical complications. Finally, some patients may have had complications treated outside of the academic medical center in which the study was performed, leading to incomplete complication data. As such, the presented complication rate may be a slight underestimate of the true complication rate in the study population. However, we believe our practice to be relatively closed, and anticipate that the proportion of missed complications is relatively low.

\section{CONCLUSIONS}

The results of this study indicate that the medical and surgical complication rates within 2 years after MIS TLIF are $15.6 \%$ and $13.6 \%$, respectively. Independent predictive factors for medical complications included prolonged operative time and diabetes mellitus. Independent predictive factors for surgical complications included age $\leq 50$, diabetes mellitus, and obesity. Patients with these risk factors should be more closely monitored during the intraoperative, perioperative, and follow-up periods for the development of complications. Additionally, these patients should be considered for preoperative complication prophylaxis when possible. More work is necessary to investigate the efficacy of risk factor modification strategies, such as weight reduction and improved glycemic control, in pre- venting medical and surgical complications after MIS TLIF.

\section{REFERENCES}

1. Singh K, Nandyala SV, Marquez-Lara A, et al. A perioperative cost analysis comparing single-level minimally invasive and open transforaminal lumbar interbody fusion. Spine J. 2014;14(8):1694-1701.

2. Seng C, Siddiqui MA, Wong KP, et al. Five-year outcomes of minimally invasive versus open transforaminal lumbar interbody fusion: a matched-pair comparison study. Spine (Phila Pa 1976). 2013;38(23):2049-2055.

3. Peng CW, Yue WM, Poh SY, Yeo W, Tan SB. Clinical and radiological outcomes of minimally invasive versus open transforaminal lumbar interbody fusion. Spine (Phila Pa 1976). 2009;34(13):1385-1389.

4. Goldstein CL, Macwan K, Sundararajan K, Rampersaud YR. Perioperative outcomes and adverse events of minimally invasive versus open posterior lumbar fusion: meta-analysis and systematic review. J Neurosurg Spine. 2016;24(3):416-427.

5. Adogwa O, Parker SL, Bydon A, Cheng J, McGirt MJ. Comparative effectiveness of minimally invasive versus open transforaminal lumbar interbody fusion: 2-year assessment of narcotic use, return to work, disability, and quality of life. $J$ Spinal Disord Tech. 2011;24(8):479-484.

6. Sulaiman WA, Singh M. Minimally invasive versus open transforaminal lumbar interbody fusion for degenerative spondylolisthesis grades 1-2: patient-reported clinical outcomes and cost-utility analysis. Ochsner J. 2014;14(1):32-37.

7. Parker SL, Mendenhall SK, Shau DN, et al. Minimally invasive versus open transforaminal lumbar interbody fusion for degenerative spondylolisthesis: comparative effectiveness and cost-utility analysis. World Neurosurg. 2014;82(1-2):230 238.

8. Joseph JR, Smith BW, La Marca F, Park P. Comparison of complication rates of minimally invasive transforaminal lumbar interbody fusion and lateral lumbar interbody fusion: a systematic review of the literature. Neurosurg Focus. 2015;39(4):E4.

9. Wong AP, Smith ZA, Nixon AT, et al. Intraoperative and perioperative complications in minimally invasive transforaminal lumbar interbody fusion: a review of 513 patients. $J$ Neurosurg Spine. 2015;22(5):487-495.

10. Terman SW, Yee TJ, Lau D, Khan AA, La Marca F, Park P. Minimally invasive versus open transforaminal lumbar interbody fusion: comparison of clinical outcomes among obese patients. J Neurosurg Spine. 2014;20(6):644-652.

11. Wang J, Zhou Y. Perioperative complications related to minimally invasive transforaminal lumbar fusion: evaluation of 204 operations on lumbar instability at single center. Spine J. 2014;14(9):2078-2084.

12. Basques BA, Anandasivam NS, Webb ML, et al. Risk factors for blood transfusion with primary posterior lumbar fusion. Spine (Phila Pa 1976). 2015;40(22):1792-1797.

13. Kim BD, Hsu WK, De Oliveira GS, Jr., Saha S, Kim JY. Operative duration as an independent risk factor for postoperative complications in single-level lumbar fusion: an analysis of 4588 surgical cases. Spine (Phila Pa 1976). 2014;39(6):510520 . 
14. Tetreault L, Ibrahim A, Cote P, Singh A, Fehlings MG. A systematic review of clinical and surgical predictors of complications following surgery for degenerative cervical myelopathy. J Neurosurg Spine. 2016;24(1):77-99.

15. Petros JG, Bradley TM. Factors influencing postoperative urinary retention in patients undergoing surgery for benign anorectal disease. Am J Surg. 1990;159(4):374-376.

16. Altschul D, Kobets A, Nakhla J, et al. Postoperative urinary retention in patients undergoing elective spinal surgery. J Neurosurg Spine. 2017;26(2):229-234.

17. Shin JI, Phan K, Kothari P, Kim JS, Guzman JZ, Cho SK. Impact of glycemic control on morbidity and mortality in adult idiopathic scoliosis patients undergoing spinal fusion. Clin Spine Surg. 2016. 30(7):E974—E980

18. Bohl DD, Mayo BC, Massel DH, et al. Incidence and risk factors for pneumonia after posterior lumbar fusion procedures: an ACS-NSQIP study. Spine (Phila Pa 1976). 2016;41(12):1058-1063.

19. Golinvaux NS, Varthi AG, Bohl DD, Basques BA, Grauer JN. Complication rates following elective lumbar fusion in patients with diabetes: insulin dependence makes the difference. Spine (Phila Pa 1976). 2014;39(21):1809-1816.

20. Guzman JZ, Iatridis JC, Skovrlj B, et al. Outcomes and complications of diabetes mellitus on patients undergoing degenerative lumbar spine surgery. Spine (Phila Pa 1976). 2014;39(19):1596-1604.

21. Tang H, Zhu J, Ji F, Wang S, Xie Y, Fei H. Risk factors for postoperative complication after spinal fusion and instrumentation in degenerative lumbar scoliosis patients. $J$ Orthop Surg Res. 2014;9(1):15.

22. Cook C, Tackett S, Shah A, et al. Diabetes and perioperative outcomes following cervical fusion in patients with myelopathy. Spine (Phila Pa 1976). 2008;33(8):E254E260.

23. Browne JA, Cook C, Pietrobon R, Bethel MA, Richardson WJ. Diabetes and early postoperative outcomes following lumbar fusion. Spine (Phila Pa 1976). 2007;32(20):2214-2219.

24. Pugely AJ, Martin CT, Gao Y, Mendoza-Lattes S. Causes and risk factors for 30-day unplanned readmissions after lumbar spine surgery. Spine (Phila Pa 1976). 2014;39(9):761-768.

25. O'Neill KR, Neuman BJ, Peters C, Riew KD. Risk factors for dural tears in the cervical spine. Spine (Phila $\mathrm{Pa}$ 1976). 2014;39(17):E1015-E1020.

26. Marbacher S, Mannion AF, Burkhardt JK, et al. Patient-rated outcomes of lumbar fusion in patients with degenerative disease of the lumbar spine: does age matter? Spine (Phila Pa 1976). 2016;41(10):893-900.

27. Buerba RA, Giles E, Webb ML, Fu MC, Gvozdyev B, Grauer JN. Increased risk of complications after anterior cervical discectomy and fusion in the elderly: an analysis of 6253 patients in the American College of Surgeons National Surgical Quality Improvement Program database. Spine (Phila Pa 1976). 2014;39(25):2062-2069.

28. Sobottke R, Aghayev E, Roder C, Eysel P, Delank SK, Zweig T. Predictors of surgical, general and follow-up complications in lumbar spinal stenosis relative to patient age as emerged from the Spine Tango Registry. Eur Spine $J$. 2012;21(3):411-417.

29. Kilincer C, Steinmetz MP, Sohn MJ, Benzel EC,
Bingaman W. Effects of age on the perioperative characteristics and short-term outcome of posterior lumbar fusion surgery. $J$ Neurosurg Spine. 2005;3(1):34-39.

30. Emami A, Faloon M, Sahai N, et al. Risk factors for pseudarthrosis in minimally-invasive transforaminal lumbar interbody fusion. Asian Spine J. 2018;12(5):830-838.

31. Hofler RC, Swong K, Martin B, Wemhoff M, Jones GA. Risk of pseudoarthrosis after spinal fusion: analysis from the Healthcare Cost and Utilization Project. World Neurosurg. 2018;120:e194-e202.

32. Gilmore SJ, Hahne AJ, Davidson M, McClelland JA. Physical activity patterns of patients immediately after lumbar surgery. Disabil Rehabil. 2019:1-7.

33. Kakar RS, Simpson KJ, Das BM, Brown CN. Review of physical activity benefits and potential considerations for individuals with surgical fusion of spine for scoliosis. Int $J$ Exerc Sci. 2017;10(2):166-177.

34. Rihn JA, Radcliff K, Hilibrand AS, et al. Does obesity affect outcomes of treatment for lumbar stenosis and degenerative spondylolisthesis? Analysis of the Spine Patient Outcomes Research Trial (SPORT). Spine (Phila Pa 1976). 2012;37(23):1933-1946.

35. Dobran M, Marini A, Nasi D, et al. Risk factors of surgical site infections in instrumented spine surgery. Surg Neurol Int. 2017;8:212.

36. Epstein NE. More risks and complications for elective spine surgery in morbidly obese patients. Surg Neurol Int. 2017;8:66.

37. Jackson KL, 2nd, Devine JG. The effects of obesity on spine surgery: a systematic review of the literature. Global Spine J. 2016;6(4):394-400.

38. Jiang J, Teng Y, Fan Z, Khan S, Xia Y. Does obesity affect the surgical outcome and complication rates of spinal surgery? A meta-analysis. Clin Orthop Relat Res. 2014;472(3):968-975.

39. Lim S, Edelstein AI, Patel AA, Kim BD, Kim JYS. Risk factors for postoperative infections after single-level lumbar fusion surgery. Spine (Phila Pa 1976). 2018;43(3):215-222.

40. De la Garza Ramos R, Nakhla J, Nasser R, et al. Effect of body mass index on surgical outcomes after posterior spinal fusion for adolescent idiopathic scoliosis. Neurosurg Focus. 2017;43(4):E5.

41. Meng F, Cao J, Meng X. Risk factors for surgical site infections following spinal surgery. J Clin Neurosci. 2015;22(12):1862-1866.

42. Haleem A, Chiang HY, Vodela R, et al. Risk factors for surgical site infections following adult spine operations. Infect Control Hosp Epidemiol. 2016;37(12):1458-1467.

43. Rao SB, Vasquez G, Harrop J, et al. Risk factors for surgical site infections following spinal fusion procedures: a case-control study. Clin Infect Dis. 2011;53(7):686-692.

Disclosures and COI: No funds were received in support of this work. No benefits in any form have been or will be received from any commercial party related directly or indirectly to the subject of this manuscript.

Corresponding Author: Kern Singh, MD, Department of Orthopaedic Surgery, Rush Univer- 
sity Medical Center, 1611 W. Harrison St, Suite 300, Chicago, IL, USA, 60612. Phone: (312) 432-2373; Fax: (708) 409-5179; Email: kern.singh@rushortho. com.

Published 30 April 2020
This manuscript is generously published free of charge by ISASS, the International Society for the Advancement of Spine Surgery. Copyright (C) 2020 ISASS. To see more or order reprints or permissions, see http://ijssurgery.com. 